University of Wollongong

Research Online

Faculty of Engineering and Information

Faculty of Engineering and Information

Sciences - Papers: Part B

Sciences

2017

\title{
Effect of groove spacing on bond strength of near-surface mounted (NSM) bonded joints with multiple FRP strips
}

Shi Shun Zhang

University of Wollongong, shishun@uow.edu.au

Tao Yu

University of Wollongong, taoy@uow.edu.au

Follow this and additional works at: https://ro.uow.edu.au/eispapers1

Part of the Engineering Commons, and the Science and Technology Studies Commons

Research Online is the open access institutional repository for the University of Wollongong. For further information contact the UOW Library: research-pubs@uow.edu.au 


\title{
Effect of groove spacing on bond strength of near-surface mounted (NSM) bonded joints with multiple FRP strips
}

\begin{abstract}
In the strengthening of existing deficient structures using the near-surface mounted (NSM) FRP method, a group of parallel NSM FRP strips are usually needed to meet the capacity enhancement requirement. When the groove spacing (i.e., the net distance between grooves) is relatively small, the bond behaviour of each NSM FRP strip is detrimentally influenced by the adjacent grooves/FRP strips, and such detrimental effect should be taken into account for a safe design of the NSM FRP strengthening system. All the existing models, however, have been proposed for NSM bonded joints with a single FRP strip and thus cannot consider the effect of groove spacing on the bond behaviour, due to the insufficiency of data from tests or numerical simulations. Against this background, a numerical parametric study, was conducted to clarify the effect of groove spacing on the bond strength of such bonded joints; the numerical parametric study involved the use of a three-dimensional meso-scale finite element model developed in the present study for NSM bonded joints with two FPP strips separately embedded in two parallel grooves. Based on the results from the parametric study, a reduction factor to account for the detrimental effect of insufficient groove spacing on the bond strength is proposed and extended to NSM bonded joints with three or more evenly-spaced FRP strips. By combining the proposed reduction factor and the bond strength model previously developed by the authors for NSM bonded joints with a single FRP strip, a bond strength model for NSM bonded joints with multiple FRP strips is proposed and the accuracy of the proposed model is verified with test results.
\end{abstract}

\section{Keywords}

groove, effect, multiple, joints, bonded, (nsm), mounted, near-surface, strips, strength, frp, bond, spacing

\section{Disciplines}

Engineering | Science and Technology Studies

\section{Publication Details}

Zhang, S. S. \& Yu, T. (2017). Effect of groove spacing on bond strength of near-surface mounted (NSM) bonded joints with multiple FRP strips. Construction and Building Materials, 155 102-113. 


\title{
Effect of Groove Spacing on Bond Strength of Near-Surface Mounted (NSM) Bonded Joints with Multiple FRP Strips
}

\author{
S.S. Zhang ${ }^{1, *}$ and T. $\mathrm{Yu}^{2}$
}

Abstract: In the strengthening of existing deficient structures using the near-surface mounted (NSM) FRP method, a group of parallel NSM FRP strips are usually needed to meet the capacity enhancement requirement. When the groove spacing (i.e., the net distance between grooves) is relatively small, the bond behaviour of each NSM FRP strip is detrimentally influenced by the adjacent grooves/FRP strips, and such detrimental effect should be taken into account for a safe design of the NSM FRP strengthening system. All the existing models, however, have been proposed for NSM bonded joints with a single FRP strip and thus cannot consider the effect of groove spacing on the bond behaviour, due to the insufficiency of data from tests or numerical simulations. Against this background, a numerical parametric study, was conducted to clarify the effect of groove spacing on the bond strength of such bonded joints; the numerical parametric study involved the use of a three-dimensional meso-scale finite element model developed in the present study for NSM bonded joints with two FPP strips separately embedded in two parallel grooves. Based on the results from the parametric study, a reduction factor to account for the detrimental effect of insufficient groove spacing on the bond strength is proposed and extended to NSM bonded joints with three or more evenly-spaced FRP strips. By combining the proposed reduction factor and the bond strength model previously developed by the authors for NSM bonded joints with a single FRP strip, a bond strength model for NSM bonded joints with multiple FRP strips is proposed and the accuracy of the proposed model is verified with test results.

Keywords: concrete; fiber-reinforced polymer (FRP); strip; near-surface mounted (NSM); groove spacing; finite element (FE) model; bond strength model

\footnotetext{
${ }^{1}$ Lecturer, School of Civil, Mining and Environmental Engineering, Faculty of Engineering and Information Sciences, University of Wollongong, Wollongong, NSW 2522, Australia (corresponding author). E-mail address: shishun@uow.edu.au.

${ }^{2}$ Senior Lecturer, School of Civil, Mining and Environmental Engineering, Faculty of Engineering and Information Sciences, University of Wollongong, Wollongong, NSW 2522, Australia.
} 


\section{$37 \quad 1$ INTRODUCTION}

38 The near-surface mounted (NSM) fiber-reinforced polymer (FRP) strengthening technique, as

39 a promising alternative to the externally bonded (EB) FRP method for structural strengthening,

40 has attracted worldwide attention over the last decade. Compared with the EB FRP method,

41 the NSM FRP method has a number of advantages, including a higher bonding efficiency and

42 a better protection of the FRP reinforcement [1]. FRP bars of various cross-sectional shapes

43 (e.g. square, round and rectangular bars) have been studied by researcher as NSM FRP

44 reinforcement. Existing experimental studies have showed that compared with other

45 cross-sectional shapes, FRP strips (i.e., rectangular bars with a large aspect ratio) possesses a

46 much better bonding efficiency (i.e., a higher local bond strength and a higher interfacial

47 fracture energy), as they have a larger perimeter-to-cross-sectional area ratio and a larger

48 embedment depth [e.g. 2-5]. In terms of material type, carbon FRP (CFRP) are thought to be

49 more attractive than other types of FRP for the application of NSM strengthening technique,

50 as CFRP usually has a higher strength and stiffness and thus could lead to a small

51 cross-sectional area with the same demand in load-carrying capacity. Therefore, CFRP strips

52 have become very popular for the use in NSM FRP strengthening and have attracted a large

53 number of studies [e.g. 1, 5-7]. As one of the fundamental issues in the application of NSM

54 FRP strengthening method, the bond strength, which is the maximum force that can be

55 developed in the FRP reinforcement in the test of bonded joints [e.g. 8, 9], has been studied

56 by a number of researchers, and several bond strength models have been proposed for NSM

57 FRP-to-concrete interfaces by directly regressing test results on NSM FRP-to-concrete

58 bonded joints [e.g. 10, 11] or conducting a numerical parametric study [e.g. 12, 13]. All the

59 existing models, however, were proposed for a single FRP strip NSM to concrete and thus

60 have not taken into account the effect of groove spacing (i.e., the net distance between

61 grooves $a_{g}$, as shown in Fig. 1) on the bond behaviour. In real application of NSM FRP 
62 strengthening method, including flexural strengthening and shear strengthening of RC

63 members, a group of parallel NSM FRP strips (as shown in Fig. 1) need to be applied to meet

64 the capacity enhancement requirement, and their bond behaviour may be detrimentally

65 influenced by the adjacent grooves/FRP strips. The detrimental effect of insufficient groove

66 spacing on the bond behaviour between NSM FRP reinforcement and concrete has not yet

67 been clarified.

\section{DETRIMENTAL EFFECT OF INSUFFICIENT GROOVE SPACING}

70 When a group of two FRP strips (separately embedded in two parallel grooves) are used in

71 the NSM strengthening method, the detrimental effect of insufficient groove spacing on the bond behaviour of each FRP strip only exists on the side where the adjacent FRP strip (referred to as adjacent FRP side for simplicity) is embedded. The bond behaviour on the other side (referred to as outer side for simplicity) is free from such detrimental effect, and thus the bond strength contributed from the outer side can be assumed to be half of the bond strength of NSM bonded joints with a single FRP strip. The difference between the total bond strength of each FRP strip and the bond strength contributed from the outer side is just the bond strength contributed from the adjacent FRP side. A reduction factor to account for such effect on the bond strength can therefore be obtained, i.e., the ratio between the bond strength from the adjacent FRP side and half of the bond strength of NSM bonded joints with a single

81 FRP strip. This reduction factor can be extended to situations where a group of three or more

82 FRP strips (embedded in evenly-spaced parallel grooves) are used. Among these FRP strips,

83 each of the two outmost FRP strips suffers the detrimental effect of insufficient groove 84 spacing from one side and thus the reduction factor only needs to be applied on one side in 85 the calculation of the bond strength of each FRP strip, while each of the inner FRP strips 86 suffers such detrimental effect from both sides and thus the reduction factor needs to be 
87 applied on both sides in the calculation of the bond strength of each FRP strip.

89 Against the above background, a three-dimensional (3-D) meso-scale finite element (FE)

90 model of bonded joints with two CFRP strips is developed, based on the FE model

91 established by Teng et al. [14] for bonded joints with a single CFRP strip whose accuracy has

92 been verified with experimental results. A numerical parametric study, covering the most

93 important parameters, is conducted in the present paper by adopting the developed FE model.

94 Based on the results of the parametric study, a reduction factor is proposed to account for the

95 effect of groove spacing on the bond strength. By introducing the proposed reduction factor

96 into the bond strength model previously proposed by the authors (Zhang et al. 2014) for

97 bonded joints with a single FRP strip, a new bond strength model is established for bonded

98 joints with multiple FRP strips. The performance of the new bond strength model is then

99 assessed with the existing test results.

\section{FINITE ELEMENT (FE) MODEL}

\section{$101 \quad 3.1$ General}

102 Based on the 3-D meso-scale model developed by Teng et al. [14] for the single-lap shear test

103 of NSM FRP strips-to-concrete bonded joints (referred to as NSM bonded joints hereafter for

104 simplicity) with a single FRP strip, the FE model for NSM bonded joints with two FRP strips

105 separately embedded in two parallel grooves (referred to as NSM bonded joints with two FPP

106 strips hereafter for simplicity) was built in the present study, using the software package

107 MSC.MARC [15]. It has been proved that the FE model established by Teng et al. [14] can

108 well predict the failure process and ultimate load of NSM bonded joints with a single FRP

109 strip, as well as the strain distributions of the FRP and the local bond-slip relationship

110 between NSM FRP strip and concrete [14]. The failure mechanism of the current case is the

111 same as that modelled in [14], with the only difference being that two FRP strips instead of 
112 one need to be included in the built FE model. Failure of NSM bonded joints may happen in

113 the materials (i.e., FRP, adhesive and concrete) or at FRP-to-adhesive/concrete-to-adhesive

114 interfaces [13, 14]. However, it has been widely accepted that in practical applications, it

115 should be guaranteed that the final failure is controlled by the failure in concrete as otherwise

116 the strengthening efficiency cannot be maximized. Existing experimental studies, in fact,

117 have proved that cohesive failure in concrete can be ensured by using an appropriate adhesive

118 (usually with a tensile strength much higher than the concrete) and by carrying out

119 appropriate surface preparation before application [13]. Therefore, in the numerical

120 simulation of NSM bonded joints, the accurate modelling of concrete material is of critical

121 importance. Following Teng et al. [14], the modelling of concrete, in particular the tensile

122 and shear behavior of the cracked concrete, was carefully treated in the present study. The

123 well-established tension-softening curve and the shear retention factor model for cracked

124 concrete were incorporated into the FE model through user-defined subroutines.

\section{$125 \quad 3.2$ FE model and boundary conditions}

126 The schematic of the NSM bond joints with two parallel FRP strips modelled in the present

127 study is shown in Fig. 2. The specimens have a height of $150 \mathrm{~mm}$ and a total length of 550

$128 \mathrm{~mm}$. The bond length of the FRP is $450 \mathrm{~mm}$, which is longer than the effective bond length

129 according to Zhang et al. [13] and Seracino et al. [9]. A length of $75 \mathrm{~mm}$ is left near the

130 loaded end to avoid local shear failure at loaded end, while a length of $25 \mathrm{~mm}$ is left near the

131 free end of the FRP strip. The concrete edge distances (i.e., $a_{e}$ in Figs. 1 and 2, the distance

132 between the outmost groove and the nearer edge of the concrete) in the specimen is changed

133 according to the height of the FRP strip, which will be introduced in details later in the

134 parametric study. Only half of the specimen is included in the FE model (Fig. 2), by taking

135 advantage of symmetry. In addition, the bottom layer of concrete block with a height of 50

136 mm was not included in the FE model. Such simplification has only marginal effect on the 
137 modeling accuracy but can significantly save the computational time [14]. The applied

138 boundary conditions include (Fig. 2): (1) the displacements in the width direction of the 139 specimen are prevented on the plane of symmetry; (2) the lower portion (with a height of 50

$140 \mathrm{~mm}$ ) of the vertical surface of the concrete block at the loaded end is restrained in the length

141 direction of the specimen; and (3) the displacement of bottom surface of the concrete block in

142 the vertical direction is restrained. First-order solid elements, which have eight nodes and full

143 Gaussian integration scheme, are used to model the concrete block, the CFRP strip and the

144 adhesive. Interfacial elements between NSM FRP and concrete are not necessary in the 145 present study, as the 3-D meso-scale FE model is able to accurately capture the debonding 146 process by using very small elements [14]. Following Teng et al. [14], very fine mesh with an 147 element size in the order of $1 \mathrm{~mm}$ are employed in building the FE model.

\section{$148 \quad 3.3$ Constitutive models}

149 The orthogonal fixed smeared crack model, which is available in MSC.MARC [15], is used

150 to model the cracked concrete. For orthogonal fixed smeared crack model, a maximum of 151 three cracks could occur at each integration point, with their directions being orthogonal to 152 each other. To eliminate the problem of mesh sensitivity, the crack band model proposed by 153 Bazant and Oh [16] is adopted in the FE model, and the tensile fracture energy of cracked 154 concrete given by CEB-FIP [17] is adopted. The yield law proposed by Buyukozturk [18] is 155 used to describe the compression-dominated behaviour of concrete (with the associated flow 156 rule), with the stress-strain behaviour being defined by the Elwi and Murray's [19] 157 compressive stress-strain curve for concrete. The initiation of cracking is detected by the 158 maximum tensile stress criterion. Hordijk’s [20] exponential softening curve is used to model 159 tension-softening behavior of cracked concrete, and Okamura and Maekawa’s [21] model is 160 used to describe the shear stress-slip behavior of cracked concrete. Both adhesive and FRP 161 are assumed to be isotropic elastic materials. The simplification in the modelling of FRP and 6 
162 adhesive was found to have nearly no effect in such simulation [14]. For more details of the

163 adopted constitutive models, the readers are referred to Teng et al. [14] or Zhang and Teng

$164[22,23]$.

1654 DESIGN OF PARAMETRIC STUDIES

$166 \quad 4.1$ Significance analysis of parameters

167 Before the above built FE model to be employed in the parametric study to investigate the

168 effect of groove spacing on the bond strength, an analysis of the involved parameters should

169 be carried out to identify the significant factors for the present study.

170

171 As the cohesion failure in the concrete near the epoxy-to-concrete interface is the failure

172 mode of interest in the present study, the strength of concrete $\left(f_{c}\right)$ is obviously one of the

173 most important parameter in determining the bond strength. A higher strength of concrete

174 gives a higher fracture energy of concrete and thus a larger bond strength. The groove

175 dimensions also have significantly effect on the bond behaviour: a deeper groove leads to a

176 larger embedment depth of the FRP strip and thus a higher confinement from the surrounding

177 concrete to the FRP strip can be expected. Therefore, the aspect ratio of the groove (i.e., the

178 groove height $h_{g}$ to groove width $w_{g}$ ratio) should be important in determining the bond

179 behavior and thus should be included in the parametric study. The thickness of the FRP strip

180 is chosen to be $2 \mathrm{~mm}$ (a typical value for commercial CFRP strips), while the height of FRP

181 strip varies in the parametric study to achieve various heights of the groove. The elastic

182 modulus of the CFRP strip in the longitudinal direction is chosen to be 150 GPa (a typical

183 value for pultruded CFRP strips).

184

185 As the adhesive was assumed to be linear-elastic material, the slip between FRP and concrete 
under a certain local bond stress is only dependent on the thickness and the shear modulus of the adhesive layer. It has been reported by Zhang et al. [12] that for commonly used adhesives in NSM CFRP strengthening technique (with an elastic modulus not larger than 5 $\mathrm{GPa}$ ), the adhesive thickness, which varies in the practical range (e.g. around 1-4 mm), has only marginal effect on the slip between the NSM FRP and concrete, as most slip is contributed by the concrete layer adjacent to the concrete-to-adhesive interface. In the present study, the elastic modulus and the thickness of adhesive are taken to be $3 \mathrm{GPa}$ and $2 \mathrm{~mm}$ respectively (both are typical values in practice).

Existing studies have shown that the bond strength of NSM bonded joint increases with the bond length, until the bond length reaches a threshold value. The threshold value of the bond

197 length has been commonly referred to as the effective bond length $\left(L_{e}\right)$ [8]. When the bond 198 length is larger than the effective bond length, any further increase in the bond length does 199 not lead to a further increase in the bond strength. In the present study, the bond length was 200 chosen to be $450 \mathrm{~mm}$, which is sufficiently large to eliminate its detrimental effect on the 201 bond strength, based on Zhang et al. [13] and Seracino et al. [9]. Furthermore, the bond strength of an NSM bonded joint can be also affected by concrete edge distances (i.e., $a_{e}$ in

203 Figs. 1 and 2). In the present study, to eliminate the detrimental effect of edge distance on the bond strength, sufficiently large values of concrete edge distance are chosen based on the height of FRP strip, according to Zhang et al. [12].

\subsection{Numerical specimens in the parametric study}

207 Based on the above considerations, the numerical specimens examined in the parametric 208 study are designed and listed in Table 1. A total of 45 specimens are analyzed in the 209 parametric study, with studied parameters covering the concrete strength, the height-to-width

210 ratio of the groove, and groove spacing. Three values of the cylinder compressive strength of 8 
211 concrete are used respectively: $20 \mathrm{MPa}, 30 \mathrm{MPa}$ and $40 \mathrm{MPa}$; three groove height-to-width

212 ratios are considered respectively: 2.33, 4.00 and 5.67. The groove height-to-width ratios are

213 achieved by changing the height of the grooves with the same width being used for all

214 numerical specimens. The width of the groove is $6 \mathrm{~mm}$, which is the summation of the

215 thickness of CFRP strip (2mm) and the thickness of the adhesive layer (2mm on each side of

216 the strip). The heights of the grooves are $14 \mathrm{~mm}, 24 \mathrm{~mm}$ and $34 \mathrm{~mm}$ respectively for CFRP

217 strips with a height of $10 \mathrm{~mm}, 20 \mathrm{~mm}$ and $30 \mathrm{~mm}$, as a $2 \mathrm{~mm}$-thick adhesive layer exists on

218 the top as well as the bottom of the strip. The maximum value of $34 \mathrm{~mm}$ is chosen based on

219 the consideration that the concrete cover thickness is not much larger than $35 \mathrm{~mm}$ in most

220 practical cases, while the minimum value of $14 \mathrm{~mm}$ corresponds to FRP strips with a

221 height-to-thickness ratio of 5, which is the lower bound for CFRP strips suggested by Zhang

222 et al. [12]. For each of the nine combinations of concrete strength and groove height-to-width

223 ratio, five values of groove spacing are chosen based on the height of the FRP strip: 0 mm,

224 20mm, 40mm, 60mm and $80 \mathrm{~mm}$ for bond joints with NSM FRP strips with a height of

225 10mm; $0 \mathrm{~mm}, 30 \mathrm{~mm}, 60 \mathrm{~mm}, 90 \mathrm{~mm}$ and 120mm for bond joints with NSM FRP strips with a

226 height of $20 \mathrm{~mm}$; and $0 \mathrm{~mm}, 40 \mathrm{~mm}, 80 \mathrm{~mm}, 120 \mathrm{~mm}$ and $160 \mathrm{~mm}$ for bond joints with NSM

227 FRP strips with a height of $30 \mathrm{~mm}$. The value of $0 \mathrm{~mm}$ of the groove spacing refers to the

228 special case in which the two FRP strips are bonded together to form a compound strip whose

229 thickness is twice of the original ones. As shown in Table 1, the name of each numerical case

230 starts with a letter "C", followed by a letter "f" and a Roman numeral to represent the

231 concrete strength $\left(f_{c}\right)$, a letter " $h$ ” and a Roman numeral to represent the height of the CFRP

232 strip $\left(h_{f}\right)$, and two letters “ag” and a Roman numeral to represent the groove spacing $\left(a_{g}\right)$.

233 For instance, Case-f20-h10-ag20 refers to the specimen which has a concrete strength of 20

$234 \mathrm{MPa}$, a FRP strip height of $10 \mathrm{~mm}$ and a groove spacing of $20 \mathrm{~mm}$. 


\section{RESULTS OF PARAMETRIC STUDY}

\section{$236 \quad 5.1$ Failure process}

237 The Specimen Case-f20-h10-ag60 is selected as an example to demonstrate the predicted

238 typical failure process of bonded joints with two FRP strips, as shown in Fig. 3, in which the

239 distribution of maximum principal cracking strains in the concrete are plotted. It can be seen

240 from Fig. 3, at the initial stage of loading, only a few cracks develop in a very small region

241 near the loaded end while most of the concrete block is still in the elastic range (Fig. 3a).

242 With the increase of the applied load, the width of cracks becomes larger (identified by the

243 color of the plotted maximum principal cracking strain) and the crack region extends in a

244 stereoscopic manner (Fig. 3b). Transverse cracks (i.e., in the plane perpendicular to the load

245 direction) form in the concrete between the two parallel grooves. These cracks are almost

246 vertical within a small layer of the concrete near the top surface of the specimen and become

247 inclined to the horizontal at an angle of around 45 degree when the depth increases. On the

248 other side of the groove (i.e., outside the region sandwiched by the two grooves), the

249 fish-spine-like cracks (i.e., cracks at around 45 degree to the loading direction) appear on the

250 top surface of the specimen. The discrepancies in the crack patterns on the two sides of the

251 groove reveal that the stress states in the concrete on the two sides of the groove are

252 significantly different from each other. This further indicates that interaction between the two

253 grooves exists during the loading process, which influences the behavior of concrete in

254 between. With the further increase in the applied load, more cracks form and the cracking

255 region gradually propagates along the bondline to the free end of NSM FRP strips (Fig. 3c).

256 At the final stage, the cracking region takes up around $60 \%$ of the bond length and does not 257 reach the edge of the concrete block (Fig. 3d), indicating that the bond length and edge

258 distance chosen for the specimen are sufficiently large to prevent their detrimental effects on

259 the bond strength. It can be clearly seen from Fig. 3d that most transverse cracks in the 10 
260 concrete sandwiched by the two grooves connect with adjacent ones at a depth of the groove 261 height, resulting in a big horizontal crack on the plane passing through the bottom surface of 262 the groove. This horizontal crack means that the concrete sandwiched by the two grooves is 263 pulled out with the two FRP strips, which agree well with the experimental observations 264 made by Rashid et al. [24].

\section{$265 \quad 5.2$ Bond strength}

266 As only half of the specimen was included in the FE modelling by taking advantage of

267 symmetry, the bond strength of the whole specimen was obtained by multiplying the ultimate 268 load directly obtained from the FE modelling by 2. The bond strengths obtained from the 269 parametric study are listed in Table 2, and the relationships between the bond strength and 270 groove spacing are plotted in Fig. 4.

272 It can be seen from Fig. 4 that: (1) a larger concrete strength or a larger height of FRP strip 273 gives a larger bond strength of the specimen, which agrees with the findings for bonded joint 274 with a single FRP strip [13]; (2) the bond strength increases with the value of groove spacing 275 but the increasing rate decreases largely with the value of groove spacing. When the value of 276 groove spacing is larger than a certain value, further increase in the groove spacing gives 277 marginal if not no increase in the bond strength. It can be seen from Table 2 that, for all 278 studied series of numerical specimens, the bond strength of the specimens with the largest 279 value of groove spacing studied in that series is very close to that with the second largest 280 groove spacing, indicating that the value of bond strength has been converged with respect to 281 the value of groove spacing.

\section{$282 \quad 5.3$ Threshold value of groove spacing}

283 In the present study, the minimum required value of groove spacing for the full development 284 of bond strength of the bonded joint with two FRP strips is termed as the threshold value of 
groove spacing (i.e., $a_{g t}$ in Table 2). The threshold value of groove spacing listed in Table 2

286 are obtained using the following steps: (1) for each of the nine series of the numerical specimens, find the best-fit four-order polynomial function to describe the relationship between the bond strength and the value of groove spacing; (2) use the obtained best-fit four-order polynomial function to calculate the value of groove spacing which corresponds to 99\% of the bond strength obtained with the largest groove spacing in that series, and this groove spacing value is treated as the threshold value of groove spacing in the present study. The threshold values of groove spacing obtained using this method are listed in Table 2.

It can be seen from Table 2 that a larger groove height (i.e., a larger FRP height) or a higher concrete strength leads to a larger threshold value of groove spacing, which is not difficult to understand: a deeper groove or a higher strength of concrete usually incurs a larger motivated stress zone around the groove and consequently a larger overlapping zone of the stress for a given value of groove spacing. To find the calculation equation for the threshold value of groove spacing, firstly, the relationship between the threshold value of groove spacing and the groove height is plotted in Fig. 5a, in which the best-fit power functions are also shown. It can be seen from Fig. 5a that the relationship between the threshold value of groove spacing and the groove height can be described by the following power function:

$$
a_{g t}=A \times h_{g}^{B}
$$

where the coefficient $A$ and the power $B$ are related to the concrete strength $f_{c}$. The relationship between the coefficient $A$ and the concrete strength is shown in Fig. 5b, and the relationship between the power $B$ and the concrete strength is shown in Fig. 5c. Based on the best-fit curves shown in Figs. 5b and 5c, two linear functions are respectively proposed for 308 the coefficient $A$ and the power $B$ :

$$
A=0.046 f_{c}+3.07
$$




$$
B=-0.002 f_{c}+1.03
$$

311 The predictions of the threshold value of groove spacing from Eq. (1) are compared with the

312 results from the FE analysis (see Table 2) in Fig. 5d, from which close agreement can be 313 observed. It can be seen from Table 2 that the ratios between predictions of Eq. (1) and FE 314 analysis have an average value of 1.003, a standard deviation (STD) of 0.024 , and a 315 coefficient of variation $(\mathrm{CoV})$ of 0.023 .

\section{$316 \quad 5.4$ Reduction factor $\beta_{g}$ accounting for the effect of groove spacing}

317 As can be seen from the parametric study, when the groove spacing is smaller than the 318 threshold value, interaction between adjacent grooves/FRP strips exists and as a result, the 319 maximum load $\overline{P_{u}}$ that could be resisted by each FRP strip in bonded joints with multiple 320 FRP strips will be smaller than the bond strength of NSM bonded joints with a single FRP 321 strip $P_{u}$. To account for this detrimental effect on the bond strength, a reduction factor $\beta_{g}$ 322 needs to be introduced as

$$
\overline{P_{u}}=\beta_{g} P_{u}
$$

324 In the present study, it is assumed that $\overline{P_{u}}$ is equal to $P_{u}$ when the groove spacing reaches

325 the threshold value $a_{g t}$. To get $\beta_{g}$, for each studied series in the parametric study, the 326 threshold value of groove spacing and the corresponding bond strength are treated as the 327 references, with respect to which other groove spacings and bond strengths are normalized 328 respectively. The normalized bond strength versus the normalized groove spacing curves just 329 represent the reduction factor $\beta_{g}$ and are shown in Fig. 6a, from which it can be seen that 330 although the curves do not perfectly coincide with each other, the scatter is very small. By 331 regressing all the points on Fig. 6a, the following equation is proposed for the reduction 332 factor $\beta_{g}$ : 


$$
\beta_{g}=-0.23\left(\frac{a_{g}}{a_{g t}}\right)^{2}+0.51\left(\frac{a_{g}}{a_{g t}}\right)+0.72 \leq 1
$$

334 Although Eq. (5) can give accurate prediction of the reduction factor, its form is relatively 335 complex. Therefore, a simplified reduction factor, described by linear function expressed in 336 Eq. (6), is also proposed and assessed in the present study.

$$
\beta_{g}=0.72+0.28\left(\frac{a_{g}}{a_{g t}}\right) \leq 1
$$

Fig. 6b shows the comparison of predictions given by Eq. (5) and Eq. (6). It can be seen from

Fig. 6b that the simplified reduction factor (Eq. 6) is close to and consistently lower than the accurate reduction factor (Eq. 5).

It should be noted that the $\beta_{g}$ in Eq. (5) or (6) is only applicable for FRP strips in bonded joints with two FRP strips and the two outmost FRP strips in bonded joints with three or more FRP strips (i.e., the detrimental effect caused by an insufficient groove spacing only exists on one side of the FRP strip). For FRP strips suffering the detrimental effect from both sides, such as the inner FRP strips in bonded joints with three or more FRP strips, the reduction factor $\beta_{g_{-} i n}$ can be obtained through the following analysis.

For FRP strips which have adjacent FRP strip on one side but not on the other side, the ultimate load that can be resisted by the FRP strip is given by

$$
\overline{P_{u}}=P_{u 1}+P_{u 2}
$$

352 Where $P_{u 1}$ is the load contributed by the bond from the side in which no adjacent FRP strip 353 exist, and can be assumed to be half of the bond strength of NSM bonded joints with a single 354 FRP strip, i.e., $0.5 P_{u}$; and $P_{u 2}$ is the load contributed by the bond from the side in which 
355 adjacent FRP strip exists, and can be expressed as $\beta_{g_{-} i n} \times\left(0.5 P_{u}\right)$. Therefore, Eq. (7) can be

356 expressed as

357

$$
\overline{P_{u}}=0.5 P_{u}+0.5 \beta_{g_{-} i n} P_{u}
$$

358 Combining Eqs. (4) and (8) gives:

$$
\beta_{g_{-} \text {in }}=2 \beta_{g}-1
$$

360

361

362

363

\subsection{Bond strength model}

Based on the above consideration, the bond strength model for bonded joints with multiple evenly-spaced FRP strips can be expressed as:

$$
P_{u_{-} m}=\left(2 \beta_{g}+\sum_{0}^{n-2} \beta_{g_{-} i n}\right) p_{u}
$$

where $n$ is the number of FRP strips; $P_{u}$ is the bond strength of NSM bonded joints with a single FRP strip and can be obtained using the equation proposed by Zhang et al. [13]:

$$
P_{u}=\sqrt{2 G_{f} E_{f} A_{f} C_{\text {failure }}} \leq P_{t} \text { when } L_{b} \geq L_{e}
$$

$$
P_{u}=\beta_{L} \sqrt{2 G_{f} E_{f} A_{f} C_{\text {failure }}} \leq P_{t} \text { when } L_{b}<L_{e}
$$

$$
\tau_{\max }=1.15 \gamma^{0.138} f_{c}^{0.613}
$$

$$
\beta_{L}=\frac{L_{b}}{L_{e}}\left(2.08-1.08 \frac{L_{b}}{L_{e}}\right)
$$

373 where $A_{f}\left(\mathrm{~mm}^{2}\right)$ is the cross sectional area of a single FRP strip; $C_{\text {failure }}(\mathrm{mm})$ is taken to be 374 the sum of the three side lengths of the groove; $E_{f}(\mathrm{MPa})$ is the elastic modulus of the FRP 
375 strip; $f_{c}(\mathrm{MPa})$ is the compressive strength of concrete cylinder; $G_{f}(\mathrm{~N} / \mathrm{mm})$ is the

376 interfacial fracture energy; $L_{b}(\mathrm{~mm})$ is the bond length; $L_{e}(\mathrm{~mm})$ is the effective bond length;

$377 P_{t}(\mathrm{~N})$ is the full tensile capacity of a single FRP strip; $\tau_{\max }(\mathrm{MPa})$ is the maximum bond

378 stress, $\gamma$ is the groove height-to-width ratio, $\beta_{L}$ the a reduction factor to consider the 379 detrimental effect of insufficient bond lengths.

3806 VERIFICATION OF THE PROPOSED BOND STRENGTH MODEL

$381 \quad$ 6.1 Comparison with FE results

382 The comparison of bond strength between the prediction of Eq. (10) and FE results for the 45

383 numerical specimens (see Table 2) are listed in Table 3 and plotted in Fig. 7. It can be seen

384 from Table 3 that, if the detrimental effect of groove spacing is ignored (i.e., the reduction

385 factor is set to 1.0), the proposed bond strength model overestimates the FE results with an

386 average prediction-to-FE load ratio of 1.142, and the scatter of the prediction is relatively

387 large with a STD of 0.152 and a $\mathrm{CoV}$ of 0.133 . If the accurate reduction factor (Eq. 5) is

388 adopted, the performance of the proposed bond strength model is largely improved, with the

389 average, STD and CoV of prediction-to-FE load ratio being 1.017, 0.011 and 0.011

390 respectively. It can be also seen form Table 3 that the proposed bond strength model with the

391 simplified reduction factor (Eq. 6) can give similarly accurate prediction to that with the

392 accurate reduction factor (Eq. 5), with the average, STD and CoV of prediction-to-FE load

393 ratio being 1.008, 0.050 and 0.050 respectively. The better performance of the bond strength

394 model with either the accurate reduction factor or the simplified reduction factor can be also

395 evidenced by the much smaller scatter of the points plotted in Fig. 7: the points predicted by

396 either the accurate reduction factor or the simplified reduction factor are very close to the

397 diagonal line (i.e., $\mathrm{y}=\mathrm{x}$ ), while most points predicted without considering the detrimental

398 effect of groove spacing are far away from the diagonal line. 


\subsection{Comparison with test results}

400 By far, a large number of experimental studies have been conducted on the bond strength of 401 NSM bonded joints [13], but most studies are for bonded joints with a single FRP strip. To 402 the best knowledge of the authors, so far the only experimental study (published in English) 403 on bonded joints with two FRP strips is from Rashid et al. [24]. There have been studies on 404 RC flexural members strengthened with multiple NSM FRP strips, such as the tests on RC 405 girders (recovered from a 42-year-old bridge) strengthened with 8 NSM CFRP strips evenly 406 embedded in 4 grooves [25] and the tests on RC beams strengthened with 8 NSM CFRP 407 strips evenly embedded in 4 grooves [26]. However, no experimental study (published in 408 English) on bonded joints with three or more NSM FRP strips was found in the open literature. In Rashid et al.'s [24] tests, two parallel CFRP strips with an aspect ratio of 16.7

410 (i.e., the height of $20 \mathrm{~mm}$ and the width of $1.2 \mathrm{~mm}$ ) were used in each specimen, with the 411 groove spacing between them being varied to study its effect on the bond strength. Recently, 412 the authors conducted a series of tests on bonded joints with two parallel CFRP strips to study 413 the effect of groove spacing, using the test setup shown in Fig. 8. In the test, the concrete 414 block has a height of 150mm, a length of $400 \mathrm{~mm}$ and a width of $300 \mathrm{~mm}$; the CFRP strip 415 had a height of $16 \mathrm{~mm}$, a thickness of $2 \mathrm{~mm}$ and a bond length of 350mm; the tensile strength and elastic modulus of the CFRP strips, averaged from three tensile specimens, were found to

417 be $2131 \mathrm{MPa}$ and $123 \mathrm{GPa}$ respectively. The details of all specimens are listed in Table 4.

419 The comparison of the bond strength between the prediction from the proposed model (i.e. Eq.

420 10) and test results are listed in Table 4 and plotted in Fig. 9. As can be seen from Table 4, if 421 the detrimental effect of groove spacing is ignored, the proposed bond strength model gives 422 an average value, a STD and a CoV of prediction-to-test load ratio of 0.987, 0.103 and 0.104 423 respectively. If the accurate reduction factor is used to consider such detrimental effect, the 
424 performance of the proposed bond strength model is improved as the STD and CoV of

425 prediction-to-test load ratio are reduced to 0.062 and 0.070 respectively. The smaller average

426 prediction-to-test load ratio of 0.889 obtained with the accurate reduction factor does not

427 mean the poor performance of the reduction factor model, in the sense that (1) the smaller

428 average prediction-to-test load ratio is caused by $P_{u}$, which was proposed to give a

429 conservative prediction of the test results (see Zhang et al. [13]); (2) the average value can be

430 easily increased by introducing an amplifying coefficient into the bond strength model,

431 without influencing the values of STD and CoV which are the more reasonable statistical

432 characteristics to judge the performance of the proposed reduction factor models. Compared

433 with the accurate reduction factor (Eq. 5), the simplified reduction factor (Eq. 6) leads to

434 nearly the same STD and CoV values of prediction-to-test load ratio (0.059 and 0.070

435 respectively), but a slightly smaller average prediction-to-test load ratio of 0.845 . The smaller

436 average value of prediction-to-test load ratio is because that the reduction factor predicted by

437 the simplified model (Eq. 5) is always smaller than that by the accurate model (Eq. 6), as

438 shown in Fig. 6. The better performance of the proposed bond strength models with either the

439 accurate reduction factor or simplified reduction factor can be also seen from the smaller

440 scatter of the points and the smaller R-squared values shown in Fig. 9. The above comparison

441 indicates that the proposed model can provide reasonably accurate and conservative 442 predictions of the test results.

\section{CONCLUDING REMARKS}

445 This paper has been concerned with the adverse effect of groove spacing (i.e., the net distance 446 between grooves) on the bond strength of NSM bonded joints with multiple FRP strips. A 447 3-D meso-scale FE model for NSM bonded joints with two FPP strips separately embedded 448 in two parallel grooves is first established, based on the FE model previously developed by 
the author [14] for NSM bonded joints with a single FRP strip. The developed FE model is then employed in a numerical parametric study to investigate the reduction of the bond strength of each NSM FRP strip caused by the adverse effect from the adjacent groove. Based on the results from the numerical parametric study, the equation for the threshold value of groove spacing (i.e., the minimum required value of groove spacing for the full development of bond strength of the bonded joint with two FRP strips) is formulated, and the bond strength model for NSM bonded joints with multiple FRP strips is proposed with two reduction factors (an accurate reduction factor and a simplified reduction factor) accounting for the adverse effect of groove spacing being introduced. Based on the findings in the present study, the following conclusions can be drawn:

(1) The bond strength of each NSM FRP strip in bonded joints with multiple FRP strips can

(2) For the parametric combinations studied herein, the threshold value of groove spacing is found to be mainly dependent on the groove height and the concrete strength. In general,

(3) Comparison of the bond strength between existing FE/test results and predictions of the proposed bond strength model verifies the accuracy of the proposed bond strength model for NSM bonded joints with two FRP strips. More experimental studies, especially on NSM bonded joints with three/more FRP strips, are still in a need for the further verification the proposed model. 


\section{ACKNOWLEDGEMENTS}

472 The authors would like to acknowledge the financial support provided by the Australian 473 Government through the Australian Research Council’s Discovery Projects funding scheme 474 (project ID: DP170102992).

475

476

\section{REFERENCES}

477 [1]. De Lorenzis, L. and Teng, J.G. (2007). "Near-surface mounted FRP reinforcement: an 478 emerging technique for strengthening structures.” Composites-Part B: Engineering, 38(2), 119-143.

[2]. Perera, W. K. K. G., Ibell, T. J., and Darby, A. P. (2013). "Bond characteristics of near surface mounted CFRP bars.” Construction and Building Materials, 43, 58-68.

[3]. Lee, D., Cheng, L.J., Hui, J.Y.G. (2013). “Bond characteristics of various NSM FRP reinforcements in concrete.” Journal of Composites for Construction, ASCE, 17(1), 117-129.

[4]. Bilotta, A., Ceroni, F., Nigro, E. and Pecce, M. (2014). "Strain assessment for the design of NSM FRP systems for the strengthening of RC members.” Construction and Building Materials, 69, 143-158.

[5]. Coelho, M.R.F., Sena-Cruz, J.M., Neves, L.A.C. (2015). “A review on the bond behavior of FRP NSM systems in concrete.” Construction and Building Materials, 93, 1157-1169.

[6]. Barros, J.A.O., Costa, I.G. and Ventura-Gouveia, A. (2011). "CFRP Flexural and Shear Strengthening Technique for RC Beams: Experimental and Numerical Research.” Advances in Structural Engineering, 14(3), 551-573.

494 [7]. Zhang, S.S., Yu, T., and Chen, G.M. (2017). "Reinforced concrete beams strengthened 495 in flexure with near-surface mounted (NSM) CFRP strips: current status and research 
needs.” Composites Part B: Engineering, under review.

497 [8]. Chen, J.F. and Teng, J.G. (2001). “Anchorage strength models for FRP and steel plates bonded to concrete.” Journal of Structural Engineering, ASCE, 127(7), 784-791.

499

[9]. Seracino, R., Jones, N.M., Ali, M.S.M., Page, M.W., and Oehlers, D.J. (2007). "Bond strength of near-surface mounted FRP strip-to-concrete joints.” Journal of Composites for Construction, ASCE, 11(4), 401-409

[10]. Seracino, R., Saifulnaz, M.R.R., and Oehlers, D.J. (2007). “Generic debonding resistance of EB and NSM plate-to-concrete joints.” Journal of Composites for

[11]. Sena Cruz, J.M., and Barros, J.A.O. (2004). "Bond between near-surface mounted carbon-fiber-reinforced polymer laminate strips and concrete.” Journal of Composites

[12]. Zhang, S.S., Teng, J.G. and Yu, T. (2013). "Bond-slip model for CFRP strips for Construction, ASCE, 8(6), 519-527.

510 [13]. Zhang, S.S., Teng, J.G., and Yu, T. (2014). "Bond strength model for CFRP strips

511 near-surface mounted to concrete.” Journal of Composites for Construction, ASCE,

512 18(3), Article Number: A4014003. doi: 10.1061/(asce)cc.1943-5614.0000402.

513 [14]. Teng, J.G., Zhang, S.S., Dai, J.G. and Chen, J.F. (2013). “Three-dimensional 514 meso-scale finite element modeling of bonded joints between a near-surface mounted 515 FRP strip and concrete.” Computers and Structures, 117, 105-117.

516 [15]. MSC.MARC (2005). User's Manual. MSC. Software Corporation, 2 MacArthur Place, 517 Santa Ana, California 92707, USA.

518 [16]. Bazant, Z. P. and Oh, B. H. (1983). "Crack band theory for fracture of concrete.” $519 \quad$ Materials and Structures, 16(93), 155-177.

520 [17]. CEB-FIP. (1990). Model Code 90, Lausanne, Switzerland, 1993 
521 [18]. Buyukozturk, O. (1977). "Nonlinear analysis of reinforced concrete structures.”

522 Computers and Structures, 7, 149-156.

523 [19]. Elwi, A. A. and Murray, D. W. (1979). “A 3D hypoelastic concrete constitutive 524 relationship.” Journal of the Engineering Mechanics Division, ASCE, 105(4), 623-641.

525 [20]. Hordijk, D. A. (1991). Local Approach to Fatigue of Concrete, PhD thesis, Delft $526 \quad$ University of Technology, 1991.

527 [21]. Okamura, H. and Maekawa, K. (1991). Nonlinear Analysis and Constitutive Models of 528 Reinforced Concrete, Tokyo: Gihodo-Shuppan.

529 [22]. Zhang, S.S. and Teng, J.G. (2014). "Finite element analysis of end cover separation in 530 RC beams strengthened in flexure with FRP”, Engineering Structures, 75, 550-560.

531 [23]. Zhang, S.S. and Teng, J.G. (2015). “End cover separation in RC beams strengthened in 532 flexure with bonded FRP reinforcement: simplified finite element approach”, Materials $533 \quad$ and Structures, 49 (6), 2223-2236.

534 [24]. Rashid, R., Oehlers, D.J., and Seracino, R. (2008). "IC debonding of FRP NSM and EB 535 retrofitted concrete: plate and cover interaction tests.” Journal of Composites for $536 \quad$ Construction, ASCE, 12(2), 160-167.

537 [25]. Aidoo, J., Harries, K. A. and Petrou, M. F. (2006). "Full-scale experimental 538 investigation of repair of reinforced concrete interstate bridge using CFRP materials,” $539 \quad$ Journal of Bridge Engineering, ASCE, 11(3), 350-358.

540 [26]. Rasheed, H. A., Harrison, R. R., Peterman, R. J. and Alkhrdaji, T. (2010). "Ductile 541 Strengthening Using Externally Bonded and Near Surface Mounted Composite 542 Systems,” Composite Structures, 92 (10), 2379-2390. 


\section{TABLES}

Table 1 Design of parametric study of groove spacing

\begin{tabular}{c|c|c|c|c|c|c|c}
\hline Specimens & $\begin{array}{c}f_{c} \\
(\mathrm{MPa})\end{array}$ & $\begin{array}{c}t_{f} \\
(\mathrm{~mm})\end{array}$ & $\begin{array}{c}h_{f} \\
(\mathrm{~mm})\end{array}$ & $\begin{array}{c}E_{f} \\
(\mathrm{GPa})\end{array}$ & $\begin{array}{c}h_{f} / t_{f} \\
(\mathrm{~mm})\end{array}$ & $\begin{array}{c}a_{e} \\
(\mathrm{~mm})\end{array}$ \\
\hline Case-f20-h10-ag0, 20,40, 60 or 80 & 20 & 2 & 10 & 150 & 5 & 60 & $0,20,40,60$ and 80 \\
\hline Case-f20-h20-ag0, 30, 60, 90, or 120 & 20 & 2 & 20 & 150 & 10 & 100 & $0,30,60,90$, and 120 \\
\hline Case-f20-h30-ag0, 40, 80, 120 or 160 & 20 & 2 & 30 & 150 & 15 & 140 & $0,40,80,120$ and 160 \\
\hline Case-f30-h10-ag0, 20,40, 60 or 80 & 30 & 2 & 10 & 150 & 5 & 60 & $0,20,40,60$ and 80 \\
\hline Case-f30-h20-ag0, 30, 60, 90, or 120 & 30 & 2 & 20 & 150 & 10 & 100 & $0,30,60,90$, and 120 \\
\hline Case-f30-h30-ag0, 40, 80, 120 or 160 & 30 & 2 & 30 & 150 & 15 & 140 & $0,40,80,120$ and 160 \\
\hline Case-f40-h10-ag0, 20,40, 60 or 80 & 40 & 2 & 10 & 150 & 5 & 60 & $0,20,40,60$ and 80 \\
\hline Case-f40-h20-ag0, 30, 60, 90, or 120 & 40 & 2 & 20 & 150 & 10 & 100 & $0,30,60,90$, and 120 \\
\hline Case-f40-h30-ag0, 40, 80, 120 or 160 & 40 & 2 & 30 & 150 & 15 & 140 & $0,40,80,120$ and 160 \\
\hline
\end{tabular}

Table 2 Threshold values of groove spacing

\begin{tabular}{|c|c|c|c|c|c|c|c|c|}
\hline \multirow[b]{2}{*}{ Specimens } & \multicolumn{5}{|c|}{ Bond strength $(\mathrm{kN})$ with different $a_{g}(\mathrm{~mm})$} & \multicolumn{3}{|c|}{$a_{g t}(\mathrm{~mm})$} \\
\hline & $0 \mathrm{~mm}$ & $20 \mathrm{~mm}$ & $40 \mathrm{~mm}$ & $60 \mathrm{~mm}$ & $80 \mathrm{~mm}$ & $\begin{array}{c}\text { FE } \\
\text { analysis }\end{array}$ & $\begin{array}{c}\text { Prediction of } \\
\text { Eq. (1) }\end{array}$ & $\begin{array}{c}\text { Prediction } \\
/ \\
\text { FE } \\
\text { analysis }\end{array}$ \\
\hline Case-f20-h10-ag0, 20,40, 60 or 80 & 38.23 & 46.68 & 51.94 & 53.29 & 53.71 & 53.4 & 54.4 & 1.020 \\
\hline Case-f30-h10-ag0, 20,40, 60 or 80 & 43.86 & 53.29 & 58.91 & 61.13 & 61.59 & 57.2 & 57.6 & 1.006 \\
\hline Case-f40-h10-ag0, 20,40, 60 or 80 & 48.34 & 58.79 & 64.94 & 67.28 & 67.91 & 59.1 & 60.2 & 1.020 \\
\hline \multirow{2}{*}{ Specimens } & \multicolumn{5}{|c|}{ Bond strength (kN) with different $a_{g}(\mathrm{~mm})$} & \multirow{2}{*}{\multicolumn{3}{|c|}{$a_{g t}(\mathrm{~mm})$}} \\
\hline & $0 \mathrm{~mm}$ & $30 \mathrm{~mm}$ & $60 \mathrm{~mm}$ & $90 \mathrm{~mm}$ & $120 \mathrm{~mm}$ & & & \\
\hline Case-f20-h20-ag0, 30, 60, 90, or 120 & 76.04 & 90.75 & 100.24 & 105.21 & 106.75 & 95.1 & 92.8 & 0.975 \\
\hline Case-f30-h20-ag0, 30, 60, 90, or 120 & 87.20 & 105.00 & 115.59 & 120.57 & 122.71 & 100.8 & 97.1 & 0.964 \\
\hline Case-f40-h20-ag0, 30, 60, 90, or 120 & 96.11 & 114.04 & 126.01 & 132.08 & 134.78 & 103.0 & 100.5 & 0.976 \\
\hline \multirow{2}{*}{ Specimens } & \multicolumn{5}{|c|}{ Bond strength $(\mathrm{kN})$ with different $a_{g}(\mathrm{~mm})$} & \multirow{2}{*}{\multicolumn{3}{|c|}{$a_{g t}(\mathrm{~mm})$}} \\
\hline & $0 \mathrm{~mm}$ & $40 \mathrm{~mm}$ & $80 \mathrm{~mm}$ & $120 \mathrm{~mm}$ & $160 \mathrm{~mm}$ & & & \\
\hline Case-f20-h30-ag0, 40, 80, 120 or 160 & 116.94 & 139.00 & 154.39 & 162.28 & 164.68 & 127.4 & 131.0 & 1.028 \\
\hline Case-f30-h30-ag0, 40, 80, 120 or 160 & 134.18 & 157.61 & 175.21 & 185.05 & 188.79 & 134.4 & 136.1 & 1.013 \\
\hline Case-f40-h30-ag0, 40, 80, 120 or 160 & 147.89 & 173.97 & 192.55 & 203.44 & 207.98 & 136.1 & 140.0 & 1.028 \\
\hline & & & & \multirow{3}{*}{\multicolumn{3}{|c|}{ Statistical characteristics }} & Average $=$ & 1.003 \\
\hline & & & & & & & STD = & 0.024 \\
\hline & & & & & & & $\mathrm{CoV}=$ & 0.023 \\
\hline
\end{tabular}


Table 3. Bond strength comparison between predictions and FE results

\begin{tabular}{|c|c|c|c|c|c|c|c|c|c|c|c|c|c|c|}
\hline & \multirow{2}{*}{$\begin{array}{c}t_{f} \\
(\mathrm{~mm})\end{array}$} & \multirow{2}{*}{$\begin{array}{c}h_{f} \\
(\mathrm{~mm})\end{array}$} & \multirow{2}{*}{$\begin{array}{c}w_{g} \\
(\mathrm{~mm})\end{array}$} & \multirow{2}{*}{$\begin{array}{c}h_{g} \\
(\mathrm{~mm})\end{array}$} & \multirow{2}{*}{$\begin{array}{c}E_{f} \\
(\mathrm{GPa})\end{array}$} & \multirow{2}{*}{$\begin{array}{c}a_{g} \\
(\mathrm{~mm})\end{array}$} & \multirow{2}{*}{$\begin{array}{c}f_{c} \\
(\mathrm{MPa})\end{array}$} & \multirow{2}{*}{$\begin{array}{l}\mathrm{FE} \\
(\mathrm{kN})\end{array}$} & \multicolumn{2}{|c|}{ Without reduction factor } & \multicolumn{2}{|c|}{$\begin{array}{l}\text { With reduction factor } \\
\text { given by Eq. (5) }\end{array}$} & \multicolumn{2}{|c|}{$\begin{array}{l}\text { With reduction factor } \\
\text { given by Eq. (6) }\end{array}$} \\
\hline & & & & & & & & & $\begin{array}{l}\text { Prediction } \\
\quad(\mathrm{kN})\end{array}$ & $\begin{array}{c}\text { Prediction } \\
/ \\
\mathrm{FE} \\
\end{array}$ & $\begin{array}{l}\text { Prediction } \\
\quad(\mathrm{kN})\end{array}$ & $\begin{array}{c}\text { Prediction } \\
/ \\
\mathrm{FE} \\
\end{array}$ & $\begin{array}{l}\text { Prediction } \\
\quad(\mathrm{kN})\end{array}$ & $\begin{array}{c}\text { Prediction } \\
/ \\
\text { FE } \\
\end{array}$ \\
\hline Case-f20-h10-ag0 & 2 & 10 & 6 & 14 & 150 & 0 & 20 & 38.23 & 54.6 & 1.428 & 39.3 & 1.028 & 39.3 & 1.028 \\
\hline Case-f20-h10-ag20 & 2 & 10 & 6 & 14 & 150 & 20 & 20 & 46.68 & 54.6 & 1.170 & 47.9 & 1.025 & 44.9 & 0.963 \\
\hline Case-f20-h10-ag40 & 2 & 10 & 6 & 14 & 150 & 40 & 20 & 51.94 & 54.6 & 1.051 & 53.0 & 1.020 & 50.6 & 0.973 \\
\hline Case-f20-h10-ag60 & 2 & 10 & 6 & 14 & 150 & 60 & 20 & 53.29 & 54.6 & 1.024 & 54.6 & 1.024 & 56.2 & 1.054 \\
\hline Case-f20-h10-ag80 & 2 & 10 & 6 & 14 & 150 & 80 & 20 & 53.71 & 54.6 & 1.017 & 54.6 & 1.017 & 61.8 & 1.151 \\
\hline Case-f20-h20-ag0 & 2 & 20 & 6 & 24 & 150 & 0 & 20 & 76.04 & 109.0 & 1.434 & 78.5 & 1.032 & 78.5 & 1.032 \\
\hline Case-f20-h20-ag30 & 2 & 20 & 6 & 24 & 150 & 30 & 20 & 90.75 & 109.0 & 1.201 & 93.9 & 1.034 & 88.4 & 0.974 \\
\hline Case-f20-h20-ag60 & 2 & 20 & 6 & 24 & 150 & 60 & 20 & 100.24 & 109.0 & 1.088 & 104.0 & 1.037 & 98.2 & 0.980 \\
\hline Case-f20-h20-ag90 & 2 & 20 & 6 & 24 & 150 & 90 & 20 & 105.21 & 109.0 & 1.036 & 108.8 & 1.035 & 108.1 & 1.028 \\
\hline Case-f20-h20-ag120 & 2 & 20 & 6 & 24 & 150 & 120 & 20 & 106.75 & 109.0 & 1.021 & 109.0 & 1.021 & 118.0 & 1.105 \\
\hline Case-f20-h30-ag0 & 2 & 30 & 6 & 34 & 150 & 0 & 20 & 116.94 & 168.2 & 1.439 & 121.1 & 1.036 & 121.1 & 1.036 \\
\hline Case-f20-h30-ag40 & 2 & 30 & 6 & 34 & 150 & 40 & 20 & 139.00 & 168.2 & 1.210 & 143.7 & 1.034 & 135.5 & 0.975 \\
\hline Case-f20-h30-ag80 & 2 & 30 & 6 & 34 & 150 & 80 & 20 & 154.39 & 168.2 & 1.090 & 159.1 & 1.031 & 149.9 & 0.971 \\
\hline Case-f20-h30-ag120 & 2 & 30 & 6 & 34 & 150 & 120 & 20 & 162.28 & 168.2 & 1.037 & 167.3 & 1.031 & 164.3 & 1.012 \\
\hline Case-f20-h30-ag160 & 2 & 30 & 6 & 34 & 150 & 160 & 20 & 164.68 & 168.2 & 1.022 & 168.2 & 1.022 & 178.7 & 1.085 \\
\hline Case-f30-h10-ag0 & 2 & 10 & 6 & 14 & 150 & 0 & 30 & 43.86 & 61.9 & 1.411 & 44.6 & 1.016 & 44.6 & 1.016 \\
\hline Case-f30-h10-ag20 & 2 & 10 & 6 & 14 & 150 & 20 & 30 & 53.29 & 61.9 & 1.162 & 53.8 & 1.010 & 50.6 & 0.949 \\
\hline Case-f30-h10-ag40 & 2 & 10 & 6 & 14 & 150 & 40 & 30 & 58.91 & 61.9 & 1.051 & 59.6 & 1.012 & 56.6 & 0.961 \\
\hline Case-f30-h10-ag60 & 2 & 10 & 6 & 14 & 150 & 60 & 30 & 61.13 & 61.9 & 1.013 & 61.9 & 1.013 & 62.6 & 1.025 \\
\hline Case-f30-h10-ag80 & 2 & 10 & 6 & 14 & 150 & 80 & 30 & 61.59 & 61.9 & 1.005 & 61.9 & 1.005 & 68.7 & 1.115 \\
\hline Case-f30-h20-ag0 & 2 & 20 & 6 & 24 & 150 & 0 & 30 & 87.20 & 123.6 & 1.418 & 89.0 & 1.021 & 89.0 & 1.021 \\
\hline Case-f30-h20-ag30 & 2 & 20 & 6 & 24 & 150 & 30 & 30 & 105.00 & 123.6 & 1.177 & 105.8 & 1.007 & 99.7 & 0.949 \\
\hline Case-f30-h20-ag60 & 2 & 20 & 6 & 24 & 150 & 60 & 30 & 115.59 & 123.6 & 1.069 & 117.1 & 1.013 & 110.4 & 0.955 \\
\hline Case-f30-h20-ag90 & 2 & 20 & 6 & 24 & 150 & 90 & 30 & 120.57 & 123.6 & 1.025 & 123.0 & 1.020 & 121.1 & 1.004 \\
\hline Case-f30-h20-ag120 & 2 & 20 & 6 & 24 & 150 & 120 & 30 & 122.71 & 123.6 & 1.007 & 123.6 & 1.007 & 131.8 & 1.074 \\
\hline Case-f30-h30-ag0 & 2 & 30 & 6 & 34 & 150 & 0 & 30 & 134.18 & 190.7 & 1.421 & 137.3 & 1.023 & 137.3 & 1.023 \\
\hline
\end{tabular}




\begin{tabular}{|c|c|c|c|c|c|c|c|c|c|c|c|c|c|c|}
\hline Case-f30-h30-ag40 & 2 & 30 & 6 & 34 & 150 & 40 & 30 & 157.61 & 190.7 & 1.210 & 162.1 & 1.029 & 153.0 & 0.971 \\
\hline Case-f30-h30-ag80 & 2 & 30 & 6 & 34 & 150 & 80 & 30 & 175.21 & 190.7 & 1.089 & 179.3 & 1.024 & 168.7 & 0.963 \\
\hline Case-f30-h30-ag120 & 2 & 30 & 6 & 34 & 150 & 120 & 30 & 185.05 & 190.7 & 1.031 & 189.0 & 1.021 & 184.4 & 0.997 \\
\hline Case-f30-h30-ag160 & 2 & 30 & 6 & 34 & 150 & 160 & 30 & 188.79 & 190.7 & 1.010 & 190.7 & 1.010 & 200.1 & 1.060 \\
\hline Case-f40-h10-ag0 & 2 & 10 & 6 & 14 & 150 & 0 & 40 & 48.34 & 67.7 & 1.400 & 48.7 & 1.008 & 48.7 & 1.008 \\
\hline Case-f40-h10-ag20 & 2 & 10 & 6 & 14 & 150 & 20 & 40 & 58.79 & 67.7 & 1.151 & 58.5 & 0.994 & 55.0 & 0.936 \\
\hline Case-f40-h10-ag40 & 2 & 10 & 6 & 14 & 150 & 40 & 40 & 64.94 & 67.7 & 1.042 & 64.8 & 0.997 & 61.3 & 0.944 \\
\hline Case-f40-h10-ag60 & 2 & 10 & 6 & 14 & 150 & 60 & 40 & 67.28 & 67.7 & 1.006 & 67.6 & 1.006 & 67.6 & 1.005 \\
\hline Case-f40-h10-ag80 & 2 & 10 & 6 & 14 & 150 & 80 & 40 & 67.91 & 67.7 & 0.996 & 67.7 & 0.996 & 73.9 & 1.088 \\
\hline Case-f40-h20-ag0 & 2 & 20 & 6 & 24 & 150 & 0 & 40 & 96.11 & 135.1 & 1.406 & 97.3 & 1.012 & 97.3 & 1.012 \\
\hline Case-f40-h20-ag30 & 2 & 20 & 6 & 24 & 150 & 30 & 40 & 114.04 & 135.1 & 1.185 & 115.1 & 1.009 & 108.6 & 0.952 \\
\hline Case-f40-h20-ag60 & 2 & 20 & 6 & 24 & 150 & 60 & 40 & 126.01 & 135.1 & 1.072 & 127.3 & 1.011 & 119.9 & 0.951 \\
\hline Case-f40-h20-ag90 & 2 & 20 & 6 & 24 & 150 & 90 & 40 & 132.08 & 135.1 & 1.023 & 134.1 & 1.015 & 131.2 & 0.993 \\
\hline Case-f40-h20-ag120 & 2 & 20 & 6 & 24 & 150 & 120 & 40 & 134.78 & 135.1 & 1.003 & 135.1 & 1.003 & 142.4 & 1.057 \\
\hline Case-f40-h30-ag0 & 2 & 30 & 6 & 34 & 150 & 0 & 40 & 147.89 & 208.5 & 1.410 & 150.1 & 1.015 & 150.1 & 1.015 \\
\hline Case-f40-h30-ag40 & 2 & 30 & 6 & 34 & 150 & 40 & 40 & 173.97 & 208.5 & 1.198 & 176.6 & 1.015 & 166.8 & 0.959 \\
\hline Case-f40-h30-ag80 & 2 & 30 & 6 & 34 & 150 & 80 & 40 & 192.55 & 208.5 & 1.083 & 195.2 & 1.014 & 183.5 & 0.953 \\
\hline Case-f40-h30-ag120 & 2 & 30 & 6 & 34 & 150 & 120 & 40 & 203.44 & 208.5 & 1.025 & 206.0 & 1.013 & 200.2 & 0.984 \\
\hline Case-f40-h30-ag160 & 2 & 30 & 6 & 34 & 150 & 160 & 40 & 207.98 & 208.5 & 1.002 & 208.5 & 1.002 & 216.9 & 1.043 \\
\hline & & & & & \multirow{3}{*}{\multicolumn{4}{|c|}{ Statistical characteristics }} & Average $=$ & 1.142 & & 1.017 & & 1.008 \\
\hline & & & & & & & & & STD $=$ & 0.152 & & 0.011 & & 0.050 \\
\hline & & & & & & & & & $\mathrm{CoV}=$ & 0.133 & & 0.011 & & 0.050 \\
\hline
\end{tabular}


Table 4. Bond strength comparison between predictions and test results

\begin{tabular}{|c|c|c|c|c|c|c|c|c|c|c|c|c|c|c|c|}
\hline & \multirow[b]{2}{*}{ Specimen } & \multirow{2}{*}{$\begin{array}{c}t_{f} \\
(\mathrm{~mm})\end{array}$} & \multirow{2}{*}{$\begin{array}{c}h_{f} \\
(\mathrm{~mm})\end{array}$} & \multirow{2}{*}{$\begin{array}{c}W_{g} \\
(\mathrm{~mm})\end{array}$} & \multirow{2}{*}{$\begin{array}{c}h_{g} \\
(\mathrm{~mm})\end{array}$} & \multirow{2}{*}{$\begin{array}{c}E_{f} \\
(\mathrm{GPa})\end{array}$} & \multirow[b]{2}{*}{$\begin{array}{c}a_{g} \\
(\mathrm{~mm})\end{array}$} & \multirow{2}{*}{$\begin{array}{c}f_{c} \\
(\mathrm{MPa})\end{array}$} & \multirow{2}{*}{$\begin{array}{l}\text { Test } \\
(\mathrm{kN})\end{array}$} & \multicolumn{2}{|c|}{$\begin{array}{c}\text { Without reduction } \\
\text { factor }\end{array}$} & \multicolumn{2}{|c|}{$\begin{array}{l}\text { With reduction factor } \\
\text { given by Eq. (5) }\end{array}$} & \multicolumn{2}{|c|}{$\begin{array}{l}\text { With reduction factor } \\
\text { given by Eq. (6) }\end{array}$} \\
\hline & & & & & & & & & & $\begin{array}{l}\text { Prediction } \\
\quad(\mathrm{kN})\end{array}$ & $\begin{array}{c}\text { Prediction } \\
/ \\
\text { FE }\end{array}$ & $\begin{array}{l}\text { Prediction } \\
\quad(\mathrm{kN})\end{array}$ & $\begin{array}{c}\text { Prediction } \\
/ \\
\text { FE }\end{array}$ & $\begin{array}{l}\text { Prediction } \\
\quad(\mathrm{kN})\end{array}$ & $\begin{array}{c}\text { Prediction } \\
/ \\
\text { FE }\end{array}$ \\
\hline \multirow{4}{*}{$\begin{array}{l}\text { Rashid et al. } \\
\text { (2008) }\end{array}$} & G30NSM & 1.2 & 20 & 3 & 22 & 161 & 30 & 20 & 102.3 & 110.8 & 1.083 & 90.0 & 0.880 & 90.0 & 0.880 \\
\hline & G40NSM & 1.2 & 20 & 3 & 22 & 161 & 40 & 20 & 124.3 & 110.8 & 0.891 & 99.7 & 0.802 & 93.4 & 0.751 \\
\hline & G50NSM & 1.2 & 20 & 3 & 22 & 161 & 50 & 40 & 118.5 & 110.8 & 0.935 & 103.1 & 0.870 & 96.8 & 0.817 \\
\hline & G70NSM & 1.2 & 20 & 3 & 22 & 161 & 70 & 40 & 135.5 & 110.8 & 0.818 & 108.1 & 0.798 & 103.6 & 0.765 \\
\hline \multirow{4}{*}{$\begin{array}{c}\text { Tests by the } \\
\text { authors }\end{array}$} & S-30-27 & 2 & 16 & 6 & 20 & 123 & 27 & 32 & 82.5 & 90.9 & 1.102 & 78.4 & 0.951 & 73.8 & 0.895 \\
\hline & S-30-54 & 2 & 16 & 6 & 20 & 123 & 54 & 32 & 98.2 & 90.9 & 0.926 & 86.9 & 0.885 & 82.2 & 0.837 \\
\hline & S-50-27 & 2 & 16 & 6 & 20 & 123 & 27 & 58 & 97.9 & 109.2 & 1.115 & 93.2 & 0.952 & 87.9 & 0.898 \\
\hline & S-50-54 & 2 & 16 & 6 & 20 & 123 & 54 & 58 & 106 & 109.2 & 1.030 & 103.2 & 0.973 & 97.2 & 0.917 \\
\hline & & & & & & \multirow{3}{*}{\multicolumn{4}{|c|}{ Statistical characteristics }} & Average $=$ & 0.987 & & 0.889 & & 0.845 \\
\hline & & & & & & & & & & STD = & 0.103 & & 0.062 & & 0.059 \\
\hline & & & & & & & & & & $\mathrm{CoV}=$ & 0.104 & & 0.070 & & 0.070 \\
\hline
\end{tabular}




\section{FIGURES}

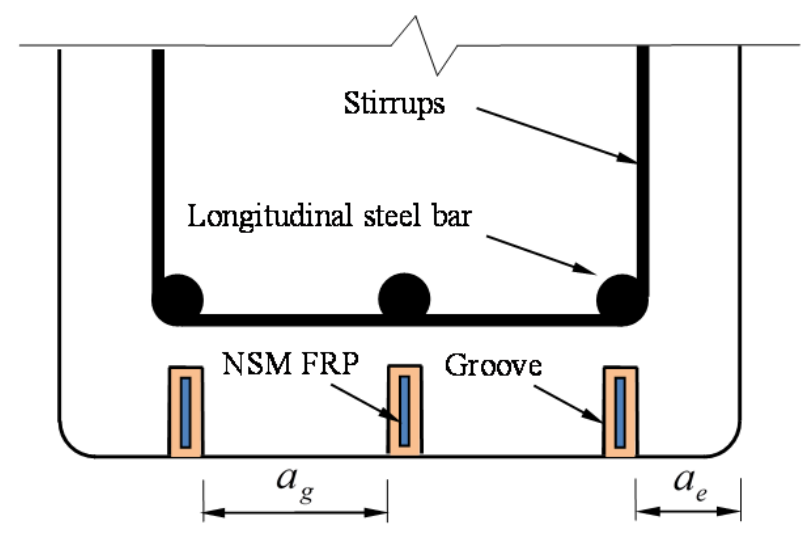

(a) Flexural strengthening
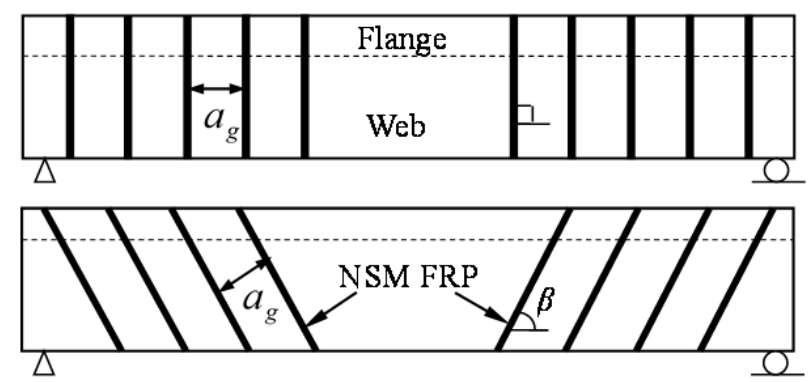

(b) Shear strengthening

Figure 1. Strengthening of RC beams using NSM FRP method 

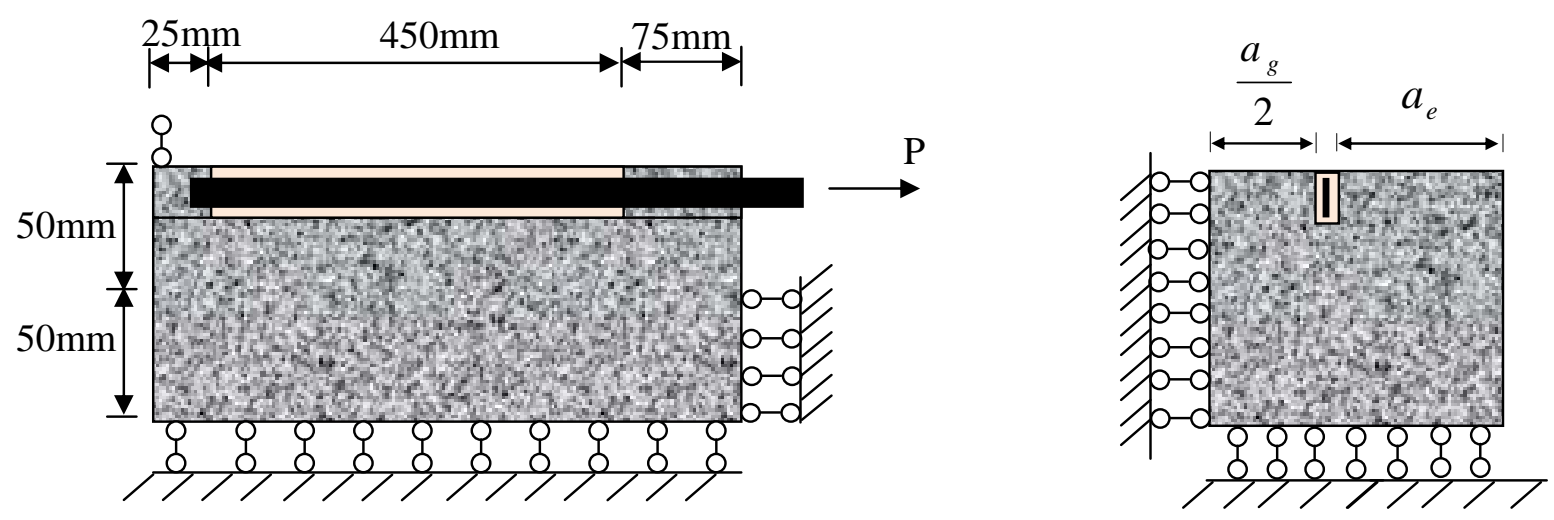

Figure 2. Schematic of the NSM bond joint in parametric studies of the groove spacing 


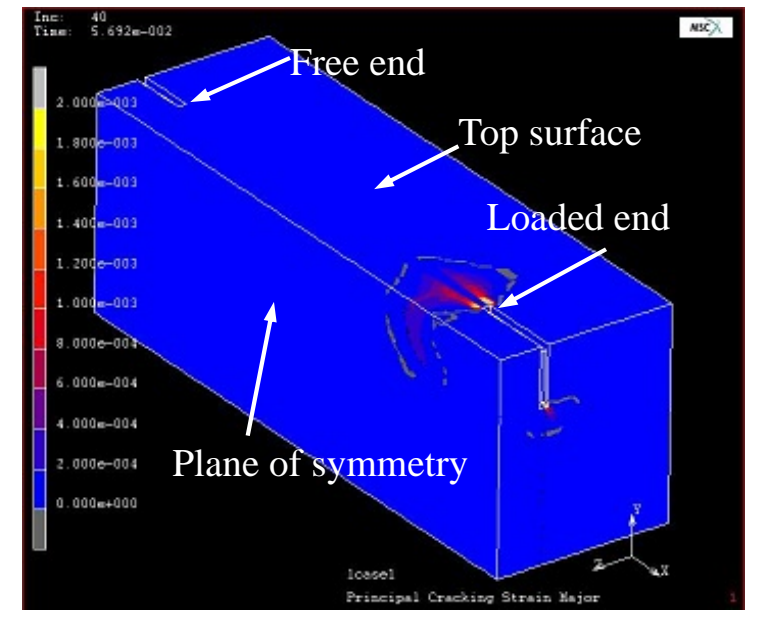

(a)

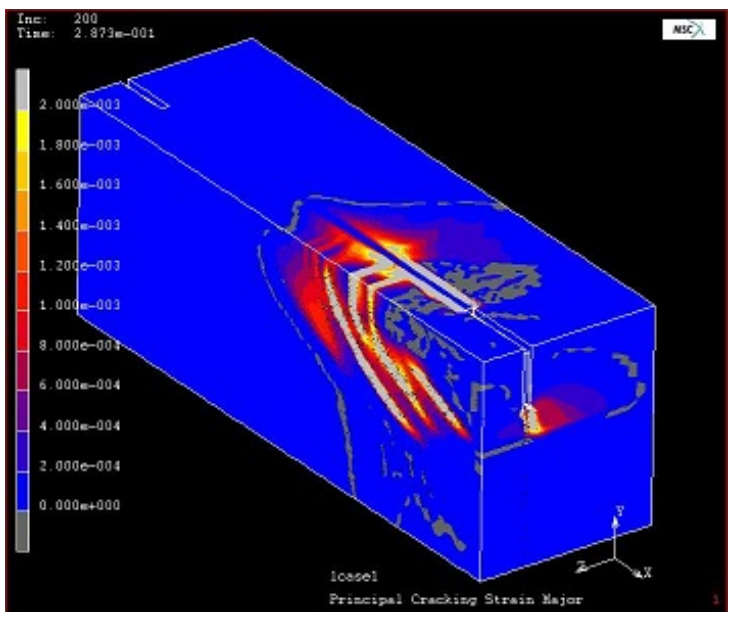

(c)

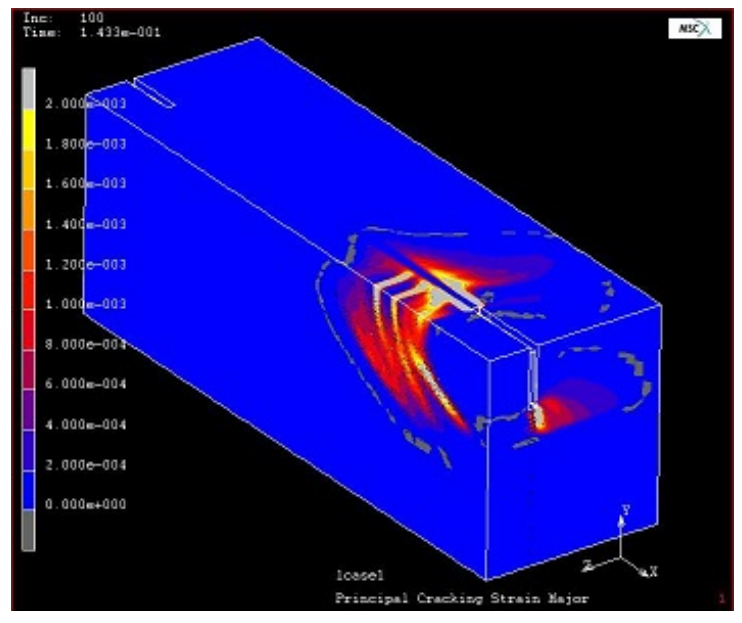

(b)

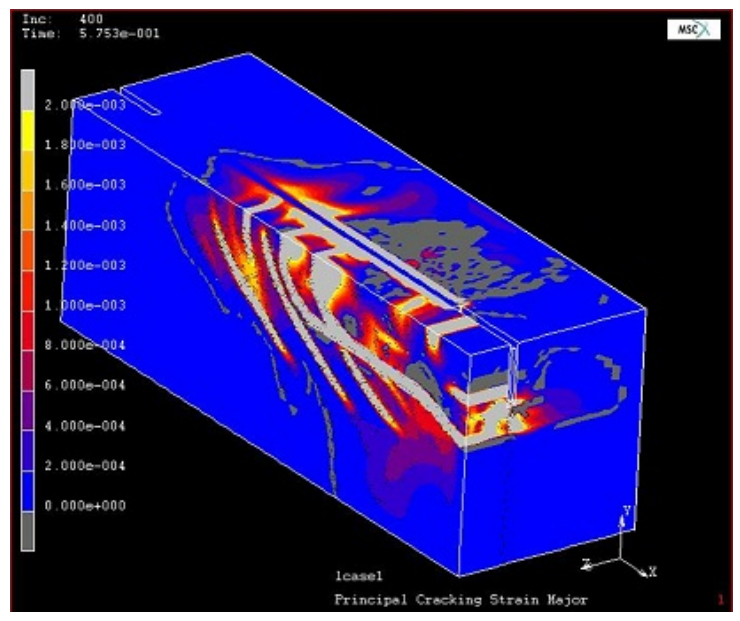

(d)

Figure 3. Failure process 


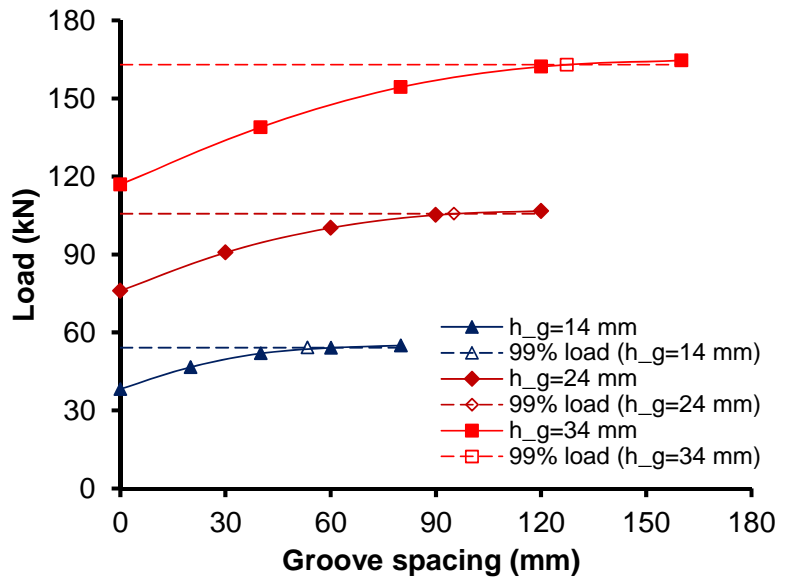

a) $f_{c}=20 \mathrm{MPa}$

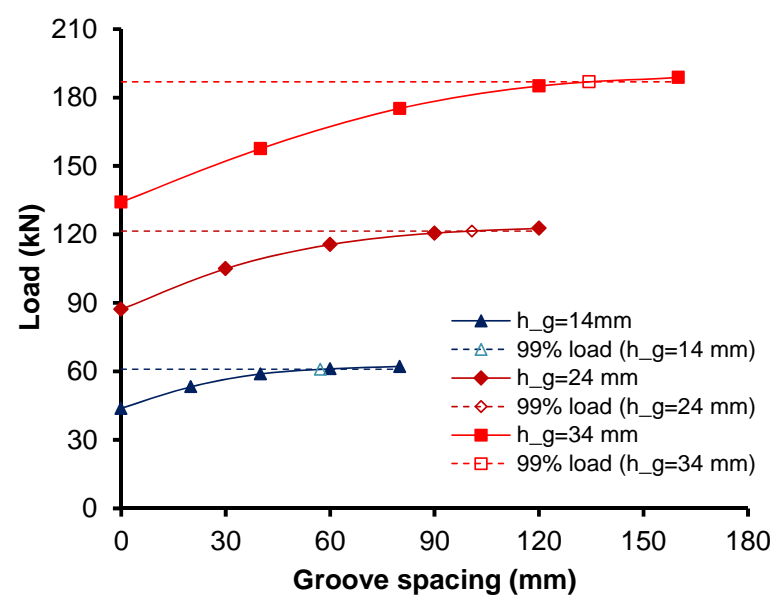

b) $f_{c}=30 \mathrm{MPa}$

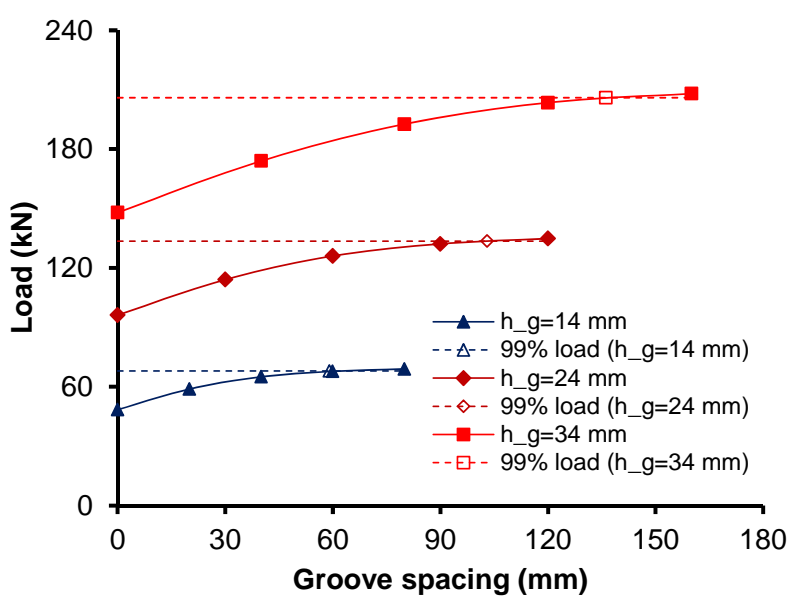

c) $f_{c}=40 \mathrm{MPa}$

Figure 4. Load versus groove spacing curves 


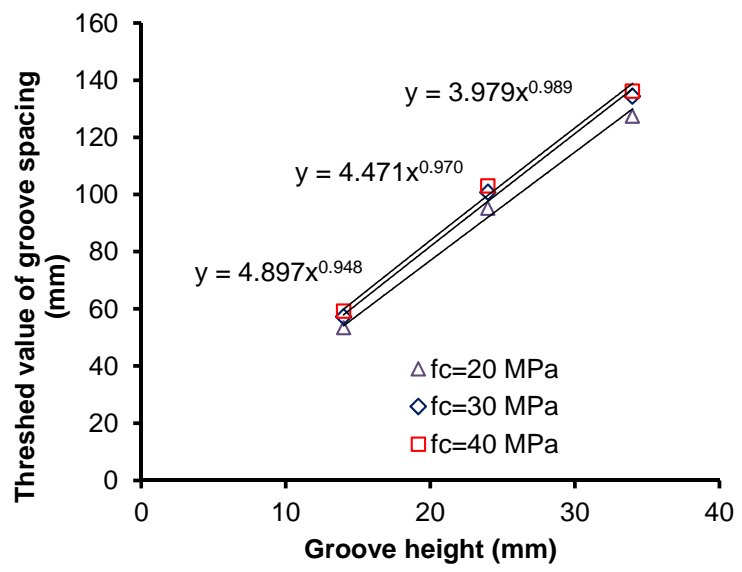

(a) Threshold value versus groove height

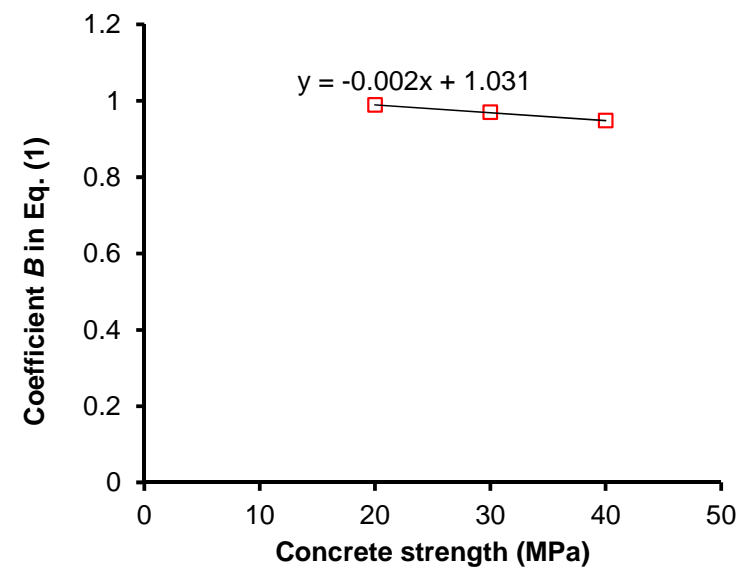

(c) Coefficient B in Eq. (1)

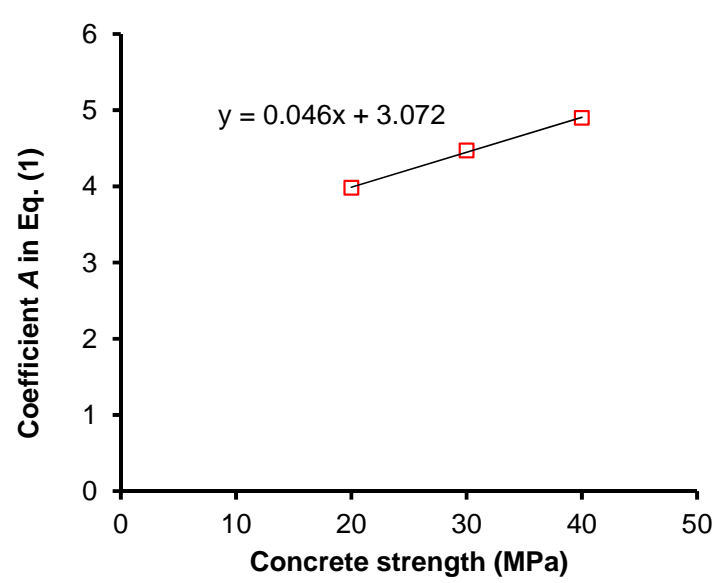

(b) Coefficient A in Eq. (1)

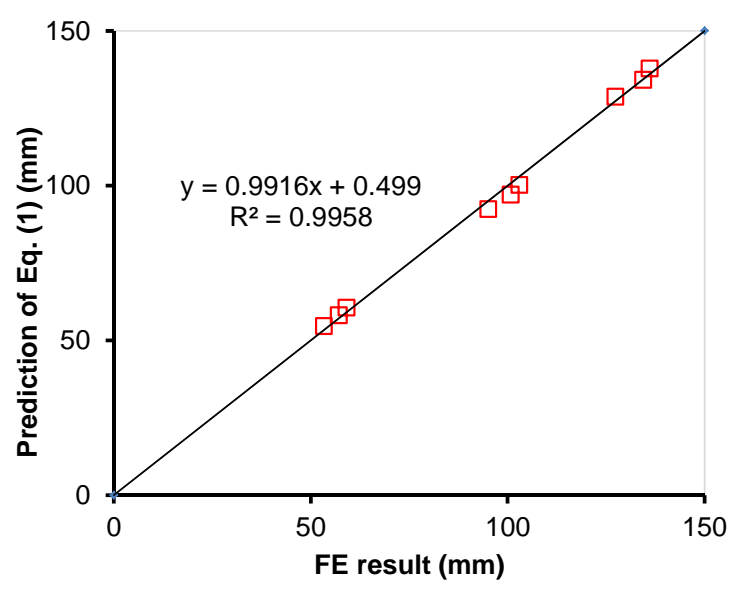

(d) verification of Eq. (1)

Figure 5. The threshold value of groove spacing 


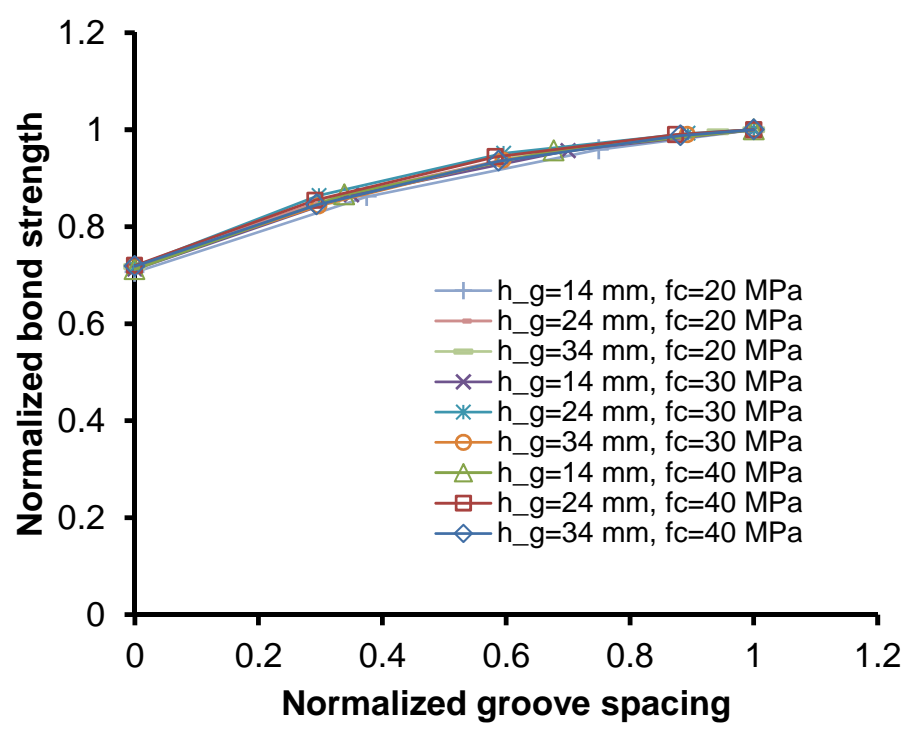

(a) Normalized bond strength versus normalized groove spacing

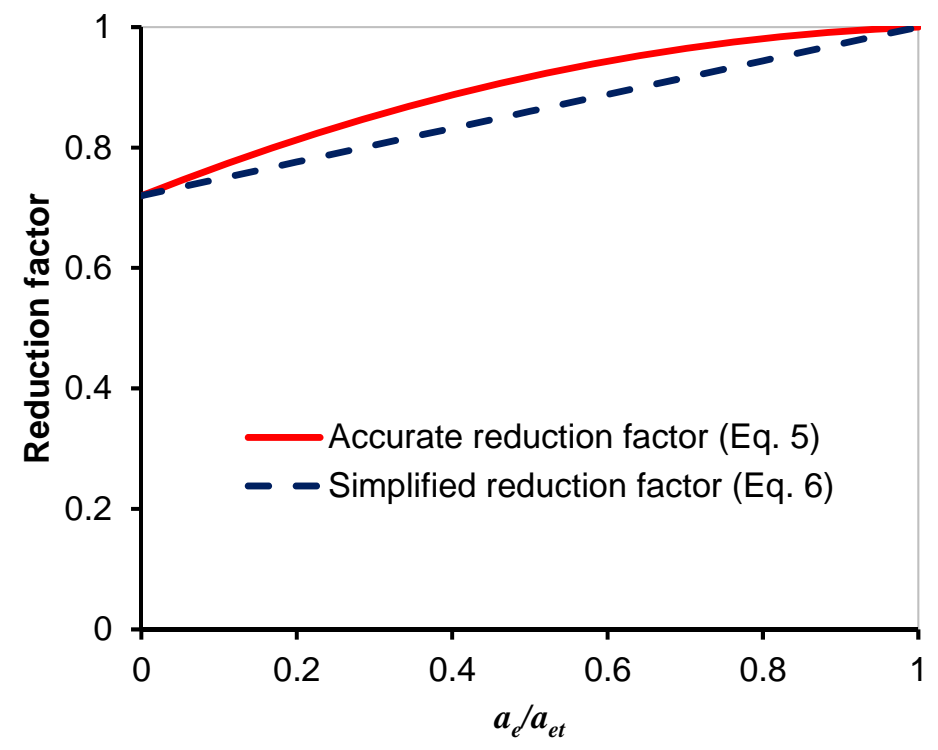

(b) Comparison of the two reduction factor models

Figure 6. Proposed reduction factors: (a) Normalized bond strength versus normalized groove spacing; (b) Comparison of the two reduction factor models 


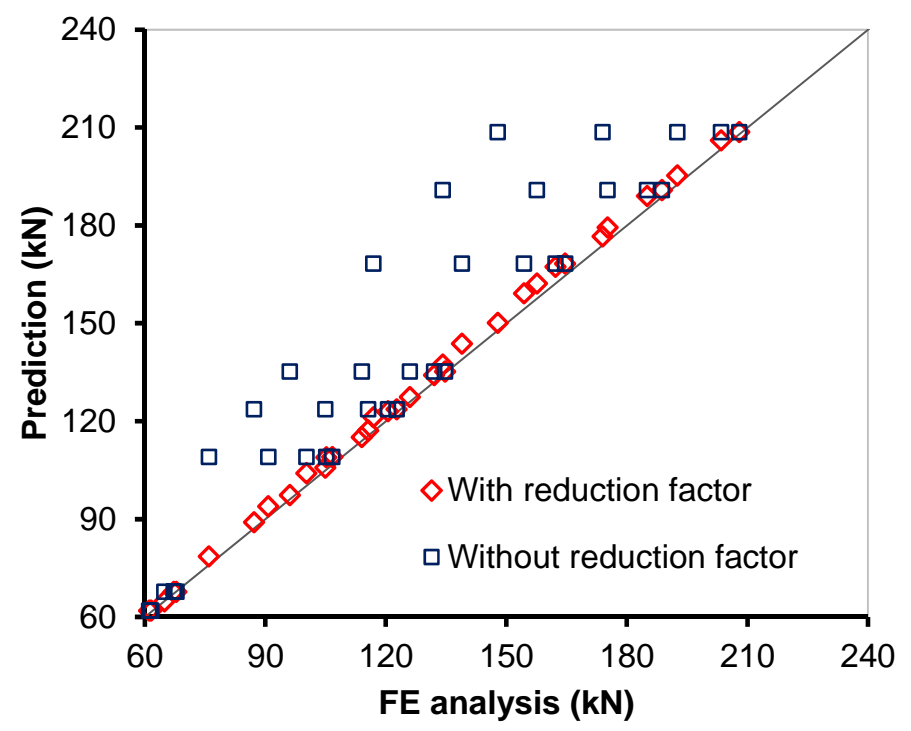

(a) Prediction using the accurate reduction factor (Eq. 5)

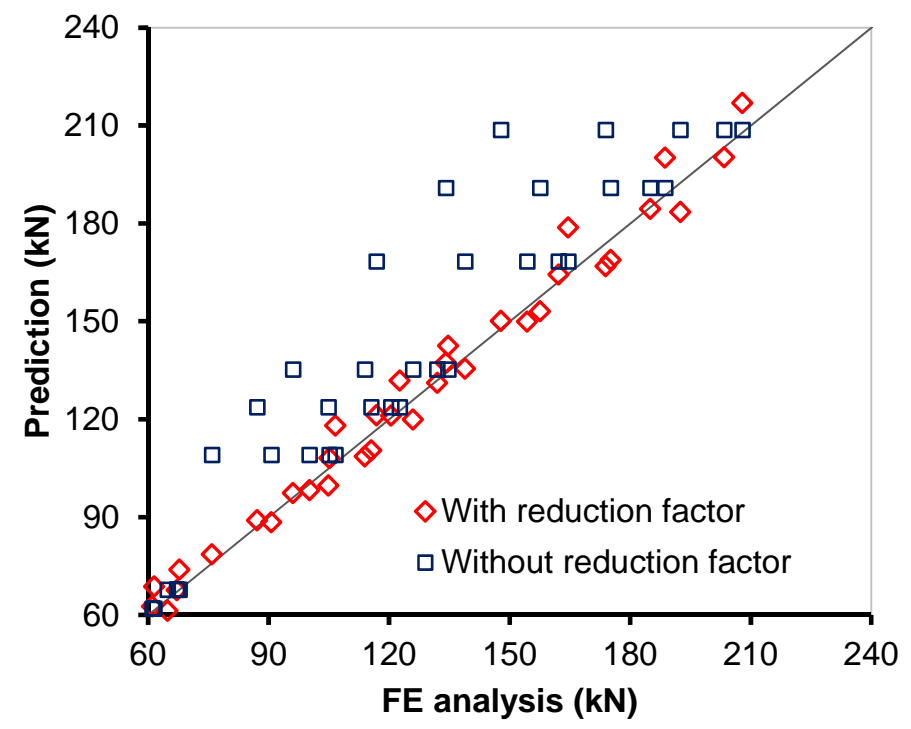

(b) Prediction using the simplified reduction factor (Eq. 6)

Figure 7. Comparison of bond strength between predictions and FE results: (a) Prediction using the accurate reduction factor (Eq. 5); (b) Prediction using the simplified reduction factor (Eq. 6) 


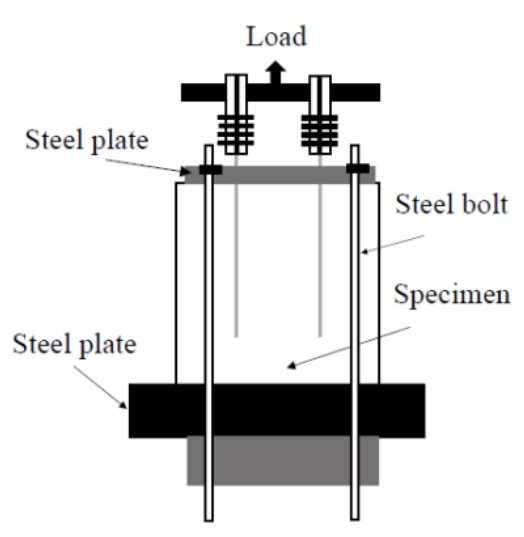

(a) test setup

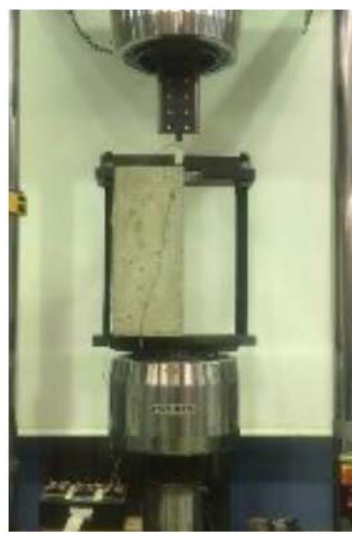

(b) side view

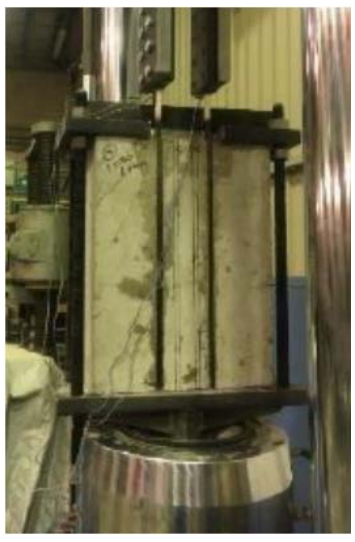

(c) front view

Figure 8. Test setup used by the authors 


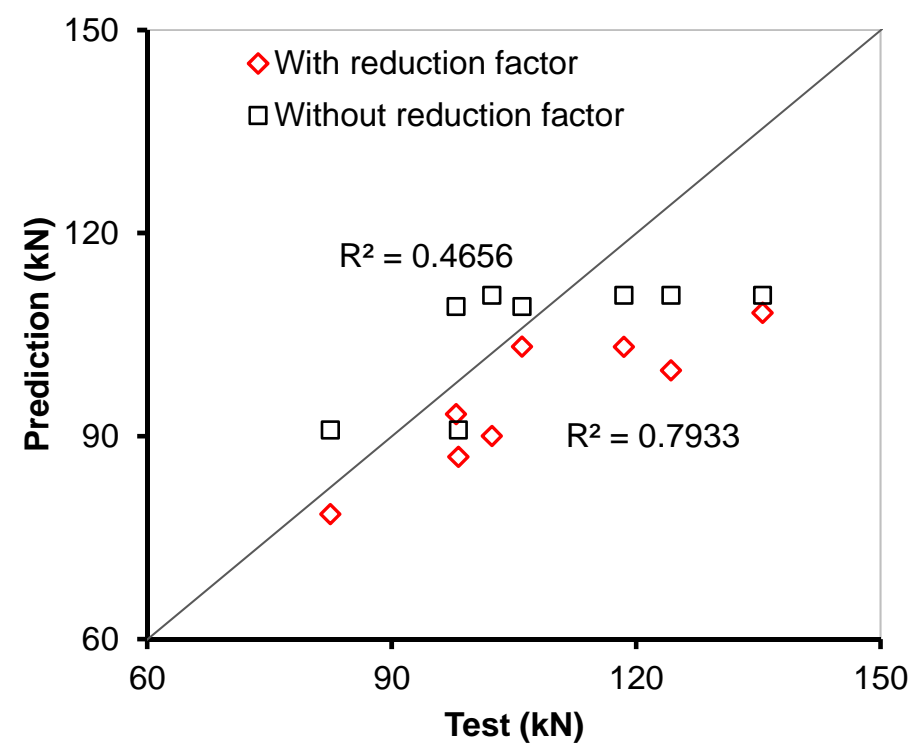

(a) Prediction using the accurate reduction factor (Eq. 5)

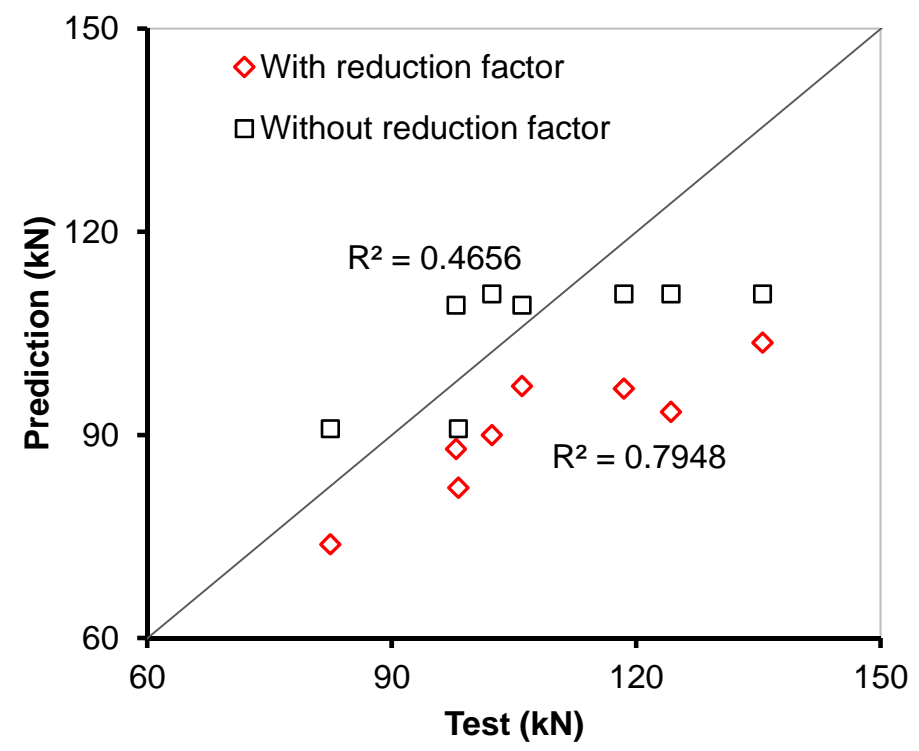

(b) Prediction using the simplified reduction factor (Eq. 6)

Figure 9. Comparison of bond strength between predictions and test results: (a) Prediction using the accurate reduction factor (Eq. 5); (b) Prediction using the simplified reduction factor (Eq. 6) 